\title{
Anger and sadness as adaptive emotion expression strategies in response to negative competence and warmth evaluations
}

\author{
Pinar Celik'*, Martin Storme' and Nils Myszkowski \\ 'Université Paris Descartes, Boulogne-Billancourt, France \\ ${ }^{2}$ Pace University, New York, USA
}

\begin{abstract}
Previous literature suggested that anger and sadness may be necessary to restore social bonds in the face of immediate relationship threat. The present research compared the social effectiveness of expressing anger and sadness in response to a negative personal evaluation. Results indicated that target anger in response to a negative competence evaluation, and target sadness in response to a negative warmth evaluation, had the most positive effects on the evaluators' subjectively perceived persuasiveness of the targets' communication (Study I) and on the subjectively perceived fluency of the interaction by both interaction partners (Study 2). Results are discussed in light of the social functionality of emotion expression and the importance of interpersonal emotion congruency with evaluation content.
\end{abstract}

Anger and sadness are in many ways related to one another. They are both negative and unpleasant emotions, and arise in negative social interactions often in parallel. The notion of 'hurt feelings' perhaps exemplifies this best, as it consists of undifferentiated negative affect like anxiety and hostility (Leary, Springer, Negel, Ansell, \& Evans, 1998). Anecdotal evidence suggests that in situations in which people expect that expressing their negative emotions is necessary to save an important relationship that is under threat, people struggle in deciding whether they should express their anger or their sadness about the situation.

Being negatively evaluated may be one of these situations in which the dilemma of choosing between anger and sadness can be especially salient. An individual receiving a negative evaluation is expected to change aspects of his or her behaviour that the evaluator has voiced concern about. Individuals who wish to address these concerns could find themselves in a difficult predicament, as they feel strong negative emotions like anger and sadness, coupled with a strong urge to express disagreement and counter the evaluator's opinion (Jussim, Yen, \& Aiello, 1995; Taylor \& Bright, 2011). The dilemma comes from the fact that expressing anger could appear both hostile, as well as strong and confident, while expressing sadness could appear warm, as well as passive and weak (Izard \& Ackerman, 2004; Kassinove, Roth, Owens, \& Fuller, 2002; Lelieveld, Van Dijk, Van Beest, \& Van Kleef, 2012; Rucker \& Petty, 2004). Both emotions could thus potentially drag the interaction further into negativity, endangering the future of the

*Correspondence should be addressed to Pinar Celik, Université Paris Descartes, 71 Avenue E. Vaillant, 92774, Boulogne-Billancourt, France (e-mail: pinar.celik@parisdescartes.fr). 
relationship, and inadvertently cause further rejection (Baumeister, 1982; Metts \& Grohskopf, 2003). Nonetheless, people often attempt to strategically feel and express their negative emotions because of possible personal and social benefits (Ford \& Tamir, 2012; Tamir \& Ford, 2012).

To date, few is known about how socially effective expressing anger is compared to expressing sadness in disagreement with a negative evaluation. The effects of negative emotion expression, and specifically the comparative study of anger and sadness, have received little attention in the context of negative interpersonal evaluation. We believe that the comparative study of anger and sadness can be an important addition to the literature in refining our understanding of the social functionality of these emotions. The goal of this study was therefore to compare the interpersonal consequences of expressing anger and sadness for targets of negative evaluation and their evaluators.

As we will outline in more detail in what follows, we distinguish between two types of evaluation content: evaluation that communicates concerns about the target's competence and evaluation that communicates concerns about the target's warmth (e.g., Cuddy, Fiske, \& Glick, 2008). Our basic premise is that anger and sadness each possess different social functional properties (Frijda, 2000), with anger being more congruent with the competence dimension of interpersonal perceptions and sadness being more congruent with the warmth dimensions of interpersonal perceptions. Therefore, we expect that depending on whether a negative evaluation communicates to an individual to improve his or her competence or warmth, either anger or sadness expression by the target should be better suited to address the evaluator's concerns, and lead to positive perceptions of the target and the interaction. Before we describe our hypotheses and studies in more detail, we first give a short overview of the relevant literature.

\section{Anger and sadness in social interactions}

Negative evaluations can occur for several reasons and in several contexts. In this study, we focus on one aspect of negative evaluations: their content. In the literature, warmth and competence are considered core and universal dimensions that people rely on when describing and judging others (Cuddy et al., 2008; Fiske, Cuddy, \& Glick, 2007). When people evaluate individuals on competence, they rely on characteristics such as skill, creativity, intelligence, and foresight, whereas when they evaluate individuals on warmth, they rely on characteristics such as friendliness, sincerity, helpfulness, deference, and benevolence. The competence-warmth distinction has been applied to study interpersonal traits (Conte \& Plutchik, 1981; Wiggins, 1979), interpersonal problems (Horowitz \& Sales French, 1979), and interpersonal relations (Wish, Deutsch, \& Kaplan, 1976).

An individual receiving a negative evaluation, either due to a perceived lack of warmth, or due to a perceived lack of competence, is expected to change certain aspects of his or her behaviour. Because the evaluator implicitly (or explicitly) communicates to the individual the prospect of potential rejection, individuals who wish to continue the relationship may feel the need to answer to the specific concerns of the evaluator and demonstrate competence and warmth. These individuals may, for example, verbally try and convince the evaluator of betterment, or attempt to bring the evaluator to doubt his or her initial judgment with arguments. The question that we ask is, in such endeavours, which emotion would be the most effective to accompany the verbal plea of the target, anger, or sadness?

The existing emotion literature is not fully clear on this. Sadness and anger (among other emotions) are both accepted in the literature as emotions that can potentially 
strengthen relational bonds in the face of relationship threat (Averill, 1983; Mikulincer, 1998). Expressing negative emotions (as opposed to suppressing them) is positively associated with psychosocial well-being, because it can help people achieve their personal goals that are social in nature (Butler et al., 2003; Gross \& John, 2003). There are, however, no studies that directly compare the effectiveness of anger expression with the effectiveness of sadness expression in negative evaluation interactions.

One possibility is that the effectiveness of anger and sadness depends on the gender of the interaction partners. For example, there are implicit cultural rules that prescribe women to express sadness and conceal their anger, and men to express anger and conceal their sadness (Timmers, Fischer, \& Manstead, 1998). Another possibility is that anger is expected to be a response to an injustice, while sadness is expected to be a response to an irrevocable loss (Ekman, 2003). As such, anger expression could be assumed to be most effective when a negative evaluation leads to (or is caused by) injustice, while sadness expression could be most effective when the negative evaluation causes irrevocable losses for the individual. A third possibility is that anger may be overall more effective than sadness, as studies indicate positive consequences of anger expression in negotiation contexts (Sinaceur \& Tiedens, 2006; Tamir \& Ford, 2012). Finally, one could also reason that sadness is overall more effective, because anger could be interpreted as hostility, and could lead to more hostility in return (Orford, 1986).

We argue, however, that alongside factors like gender rules, or perceptions of injustice or loss, the very content of the evaluation itself - that is, competence or warmth - may be a prime determinant of how effective sadness and anger expressions are in the interaction between an evaluator and target of the evaluation. Specifically, we propose that the effectiveness of anger and sadness may partly depend on whether their expression is congruent with the content of the negative evaluation.

\section{Social congruency of emotion expression}

When one is suddenly confronted with a poisonous snake that is ready to attack, expressing fear would probably be a more functional response than expressing joy. This is because fear causes adrenaline to spike and prepares the body to hide, attack, or flee, whereas joy does not (Cosmides \& Tooby, 2000). Likewise, expressing anger and sadness may be especially functional in situations of negative warmth and competence evaluation, because compared to positive emotions, they signal and call for behavioural change and improvement (Brown \& McConnell, 2011). Moreover, literature suggests that the functional properties of anger and sadness resonate with the fundamentally distinct behaviours, intentions, and qualities associated with, respectively, competence and warmth characteristics of individuals. Specifically, anger may be more congruent with the competence dimension than with the warmth dimension, whereas sadness may be more congruent with the warmth dimension than with the competence dimension.

We define social congruence of emotions as the 'match' or harmony between expressed (and/or felt) emotions, and the social context. As such, social congruency of emotions refers to the functionality of emotions. From a functionalist perspective, emotions can be seen as processes that ultimately function to activate and direct goalrelated behaviours (Tooby \& Cosmides, 2008). Different emotions are each theorized to fulfil distinct signalling functions of intra- and interpersonal intentions, and they directly evoke distinct behavioural impulses, with each emotion activating specific 'readiness potentials' for certain actions (Ekman, 1992; Frijda, 2000; Tooby \& Cosmides, 2008; Van 
Kleef, 2010). In this view, each emotion is thus a more or less potent response to specific demands in the social context of the individual.

Literature shows that sadness and anger communicate different intentions and qualities when expressed, and activate within the individual different relationship goals and readiness potentials that are congruent with, respectively, warmth-and competencerelated behaviours. Sadness, for example, communicates one's friendly and benevolent intentions and elicits nurturance from others (Burgoon, Guerrero, \& Manusov, 2011; Vingerhoets, Cornelius, Van Heck, \& Becht, 2000; Zeifman, 2001). Within the individual, sadness leads to feelings of helplessness and motivates the individual to actively reach out to others (Gray, Ishii, \& Ambady, 2011; Shaver, Schwartz, Kirson, \& O'Connor, 1987). Anger, on the other hand, signals dominance and toughness and motivates the individual to reassert his or her strength and competence (Kassinove et al., 2002; Keltner \& Haidt, 1999; Knutson, 1996; Shaver et al., 1987; Sinaceur \& Tiedens, 2006; Van Beest, Van Kleef, \& Van Dijk, 2008; Van Kleef, 2010). People expressing anger subjectively feel stronger, are perceived as being of higher status, and are also given more status than people expressing sadness (Tiedens, 2001; Tiedens, Ellsworth, \& Mesquita, 2000).

In short, expressing sadness, together with down-regulating anger, signals one's warmth and friendly intentions and prepares the individual to engage in (and receive) communal behaviours like helping and nurturing. Expressing anger, on the other hand, signals one's strength, power, and competence and prepares the individual for behaviours that aid in building competence (Timmers et al., 1998). Therefore, a negative competence evaluation may be more effectively addressed by expressing anger, than by expressing sadness, whereas a negative warmth evaluation may be more effectively addressed by expressing sadness, than by expressing anger.

In support of this idea, studies found that in negative evaluation situations what people feel-anger or sadness - depends on whether they were evaluated as lacking warmth, or as lacking competence (Çelik, Lammers, Van Beest, Bekker, \& Vonk, 2013). In their studies, Çelik et al. (2013) informed participants about how they had been graded by a potential interaction partner on several traits related to competence and warmth, based on a short and minimally informative exchange of personal information. Half of the participants then learned that their assigned partner did not want to continue with them anymore. Results showed that rejected participants responded with more anger than sadness to negative competence evaluations and with more sadness than anger to negative warmth evaluations.

If it is true that this selectivity in study participants' subjective emotion experience (i.e., 'anger over sadness' and 'sadness over anger') represents a readiness potential to engage in action (Frijda, 2000), these individuals seemed to be 'gearing up' to demonstrate either their warmth or their competence, depending on whether they had been negatively evaluated on their warmth or on their competence. As participants in these studies were not expecting to meet their evaluator, the selective activation of these emotion systems supports the idea of an evolved and hardwired emotion mechanism (Cosmides \& Tooby, 2000). Crucially, this could also mean that observing and expressing socially congruent anger and sadness could lead to more positive interpersonal consequences, than observing and expressing incongruent anger and sadness.

In sum, we argue that whether expressing sadness or anger in response to a negative evaluation has the most positive interpersonal consequences could partly depend on the (in) congruence of their expression with the content of the evaluation - that is, warmth or competence. In situations in which receiving a negative evaluation motivates individuals 
to persuade their evaluator to revise his/her negative opinion in a more positive direction, we argue that congruently expressing either anger or sadness (compared to incongruently expressing them) could potentially have the evaluator doubt his/her initial opinion more, and positively influence perceptions of the quality of the interaction. We test our ideas in two studies that we shortly introduce below.

\section{Study overview}

We hypothesize that in response to a negative competence evaluation, an angry disagreement should lead to more positive interpersonal outcomes than a sad disagreement. Conversely, we hypothesize that in response to a negative warmth evaluation, a sad disagreement should lead to more positive interpersonal outcomes than an angry disagreement. Consequently, we investigate whether selectively emphasizing anger or sadness in a socially congruent manner - that is, by matching reactions of anger and sadness respectively to an evaluation of lack of competence and lack of warmth - produces effective interpersonal outcomes, compared with incongruent emotion expression.

In two studies, we focus on the interaction between evaluators and targets that either lack warmth or lack competence. In Study 1, our main dependent variable is the evaluators' perceived persuasiveness of the targets' disagreement with the evaluation. We hypothesize that relative to incongruent expressions of anger and sadness, congruent expressions of anger and sadness will increase the subjectively perceived persuasiveness of the target and increase the extent to which the evaluator doubts his/her initially negative opinion.

In Study 2, we assess a more intuitive measure of effectiveness of anger and sadness expressions and focus on subjective perceptions of easiness and naturalness of the interaction in a staged negative evaluation interview. The ease with which an interaction is processed has been identified in the literature as an indicator of interaction quality (Zitek \& Tiedens, 2012). In short, interactions that are more easily processed are interactions that function well. In daily life, these interactions are more often repeated and encountered, which further feeds a sense of naturalness and familiarity (Zitek \& Tiedens, 2012). Literature suggests that high processing fluency is accompanied by a 'feeling right' experience, which increases liking, trust, and perceptions of truth, and facilitates intergroup communication (Alter \& Oppenheimer, 2009; Pearson \& Dovidio, 2013; Reber, Meier, Ruch-Monachon, \& Tiberini, 2006; Zitek \& Tiedens, 2012). We hypothesize that congruent expressions of anger and sadness will increase processing fluency of the interaction, relative to incongruent expressions of anger and sadness.

\section{STUDY I}

In this study, evaluators were real-life managers in companies. Negative evaluations frequently occur on the work floor, and subordinates often disagree with them (Ilgen \& Davis, 2000). Considering that anger expressions are highly condemned, especially on the work floor (Kramer \& Hess, 2002), testing our research questions with managers provided a strong test of our hypothesis.

Managers read and imagined negatively evaluating a hypothetical employee about his/her comportment on the work floor, which concerned either the employee's warmth or the employee's competence. Employees in the scenarios either responded with an angry or a sad plea of disagreement to the evaluation. We hypothesized that 
emotion congruency of the employee's response with the content of the evaluation would increase the perceived persuasiveness of the target's disagreement with the evaluation, compared with emotion incongruency. In other words, because anger expresses the motivation and readiness to compete and work harder, a supervisor who is concerned about an employee's competence should be more convinced by an angry disagreement with the evaluation, than a sad one. In the same vein, because sadness expresses the readiness to build trust and friendship, a supervisor who is concerned about an employees' warmth should be more convinced by a sad disagreement with the evaluation, than with an angry one.

Literature shows that expressed emotions can alter observers' and interaction partners' attitudes and opinions towards the expresser in a positive direction (Côte \& Hideg, 2011; Van Kleef, Van Doorn, Heerdink, \& Koning, 2011). Therefore, we additionally hypothesized that an angry disagreement should enhance managers' perceptions of employees' competence, relative to warmth, while a sad disagreement should enhance perceptions of the employees' warmth, relative to competence.

\section{Method}

\section{Participants and design}

We recruited 343 managers ( 158 women; $M_{\text {age }}=35.56$ years, $S D_{\text {age }}=14.90$, ranging between 18 and 68 years of age) to participate in the study. Participants had to have at least one direct subordinate to be included in the study. Managers were recruited by business students as part of a course project. Managers participated voluntarily and received no compensation for their participation. They were randomly allocated to one of four types of negative evaluation scenarios.

\section{Materials}

\section{Negative evaluation scenarios}

To manipulate emotion congruency, we devised four hypothetical scenarios that varied according to two factors: the content of the evaluation and the emotional response of the employee. In all scenarios the hypothetical employee responded with disagreement to the negative evaluation and expressed the desire to prove to the manager that he/she is wrong. In half of the scenarios, managers imagined that they gave a fictional employee (whose gender was not mentioned) a negative competence evaluation, and in the other half, a negative warmth evaluation:

Your performance is really below the standard of the department, you are incompetent and unproductive [Your attitude in the department is very negative, you are cold and disagreeable]. If your performance does not improve, we will have to fire you.

This was crossed with the employee's emotional reaction to the evaluation. Thus, in half of the scenarios the employee expressed disagreement with sadness, and in the other half, with anger:

I do not agree with you, and what you are telling me makes me feel very angry [sad]. If you give me time, I will show you that I am neither incompetent [cold], nor unproductive [disagreeable]. 


\section{Dependent variables}

We assessed managers' perceptions of the persuasiveness of the employee's response with two items, 'To what extent would the employee's reaction make you doubt your initial evaluation?' and 'To what extent would you be convinced by the employee's response?' (Cronbach's $\alpha=.74$ ).

Next, employee's warmth and competence were assessed with 6 items each (e.g., 'In a situation like this, to what extent would you think that the employee is warm [competent]?', Cronbach's $\alpha$ 's were, respectively, .88 and .86). All items were administered with a horizontal slider scale ranging from 0 'not at all' to 100 'totally', in 1-point increments. Respondents simply clicked or dragged the slider to indicate their preference point. ${ }^{1}$

\section{Procedure}

Managers completed the test via an online survey. They were randomly presented with one of the four scenarios and were instructed to read it carefully and imagine themselves in the situation. We specifically asked how the employee's response would make them feel and think. Managers were then asked to answer questions about the scenario by adopting a manager's perspective.

\section{Results}

\section{Effects on employee's persuasiveness}

A one-way ANOVA with emotion congruency (congruent vs. incongruent) as the independent variable, and persuasiveness as the dependent variable, revealed that in the congruent condition employee disagreement was perceived as more persuasive $(M=49.10, S E=1.56)$ than in the incongruent condition $(M=43.68, S E=1.47), F$ $(1,341)=6.38, p=.012, \eta_{p}^{2}=.018$. Adding gender and its interaction with emotion congruency to the analysis did not an change this effect, $F(1,339)=5.96, p=.015$, $\eta_{p}^{2}=.017$. Gender had no main effect, nor an interaction effect with congruency, $p ' s>.23$.

Next, we teased apart the effects of emotion and evaluation content in a two emotional reaction (angry vs. sad) $\times 2$ evaluation content (warmth vs. competence) ANOVA. As expected, a significant interaction effect emerged, $F(1,339)=5$. 96, $p=.015, \eta_{p}^{2}=.017$. None of the other effects were significant, $F$ s $<1$. The interaction was in the expected direction. When the evaluation was on warmth, sadness was considered more persuasive $(M=48.96, S E=2.24)$ than anger $(M=40.80, S E=2.02)$, whereas when the evaluation was on competence, anger was considered more persuasive $(M=49.22, S E=2.16)$ than sadness $(M=46.94, S E=2.14)$. Pairwise comparisons showed that persuasiveness scores were significantly higher in the warmth-sadness condition than in the warmth-anger condition, $F(1,339)=7.35$, $p=.007, \eta_{p}^{2}=.021$. Moreover, in the competence-anger condition, persuasiveness scores were significantly higher than in the warmth-anger condition, $F(1,339)=8.14$, $p=.005, \eta_{p}^{2}=.023$. See Figure 1 .

\footnotetext{
' In neither study, observations were excluded, and we report all administered measures/items and experimental conditions. Sample size was not determined a priory, and sampling was stopped after no more data could be required.
} 


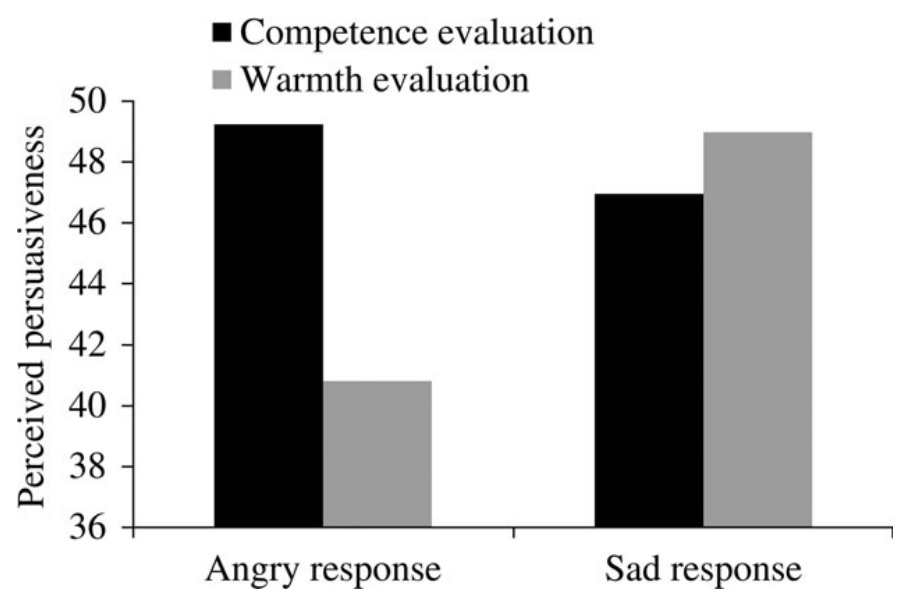

Figure I. Anger was perceived to be more persuasive when it was in response to a negative competence evaluation, while sadness was perceived to be more persuasive when it was in response to a negative warmth evaluation.

\section{Effects on perceived employee warmth and competence}

A 2 emotional reaction (angry vs. sad) $\times 2$ employee perception (warmth and competence, within-subjects variable) between-within mixed ANOVA revealed a significant main effect of emotional reaction, $F(1,341)=14.45, p<.001, \eta_{p}^{2}=.041$. Overall, perceptions of warmth and competence were higher for employees expressing sadness $(M=46.73, S E=0.92)$ than for employees expressing anger $(M=41.90$, $S E=0.88)$. Importantly, there was also a significant emotional reaction $\times$ employee perception interaction effect, $F(1,341)=14.15, p<.001, \eta_{p}^{2}=.040$. Simple comparison tests showed that perceptions of competence $(M=43.13, S E=0.95)$ were higher than perceptions of warmth $(M=40.66, S E=1.01)$ for employees expressing anger, $F(1$, $341)=7.87, p=.005, \eta_{p}^{2}=.023$. Perceptions of warmth $(M=47.89, S E=1.06)$, on the other hand, were higher than perceptions of competence $(M=45.56, S E=0.99)$ for employees expressing sadness, $F(1,341)=6.37, p=.012, \eta_{p}^{2}=.018$. Adding gender to the analysis did not meaningfully change these results; the interaction effect was still significant, $F(1,339)=13.60, p<.001, \eta_{p}^{2}=.039$, and in the same direction. No main effect of gender or interaction effects emerged, $p$ 's $>$.489. See Figure 2.

\section{Discussion}

This study showed that managers' perceptions of the persuasiveness of the employee's response and their opinion about the employee's competence and warmth were both positively affected by anger and sadness expressions. Specifically, anger increased perceptions of competence (relative to warmth), and as a response to a competence evaluation anger appeared more persuasive than sadness. Sadness on the other hand, increased perceptions of warmth (relative to competence), and as a response to a warmth evaluation sadness appeared more persuasive than anger. This study confirmed our idea that anger is more effective than sadness in response to a negative competence evaluation, while sadness is more effective than anger in response to a negative warmth evaluation.

This first study assessed evaluators' explicit appraisals of targets' anger and sadness expressions and as such measured the effect of anger and sadness on relatively rational and 


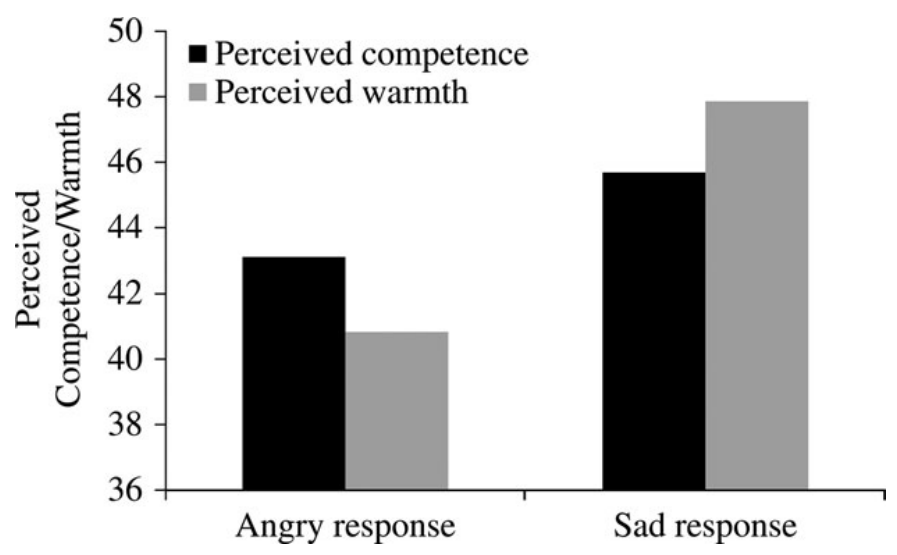

Figure 2. Anger increased perceptions of competence relative to perceptions of warmth, while sadness increased perceptions of warmth relative to perceptions of competence.

deliberative processes in social interactions. To extend our findings, in the next study we focused on a more intuitive aspect of social interactions and measured perceptions of interaction fluency (Pearson \& Dovidio, 2013) in a staged interaction between evaluators and targets. In doing this, we also took into account the perceptions of targets to obtain a more comprehensive understanding of the effects of sadness and anger expressions in negative evaluation interactions.

\section{STUDY 2}

In this study, we assessed mutual perceptions of processing fluency of the interaction between evaluators and targets during a staged negative evaluation interview using a roleplaying paradigm. Candidates in a job interview were rejected for a job, because they were evaluated by recruiters as either lacking warmth, or lacking competence. Candidates were instructed to enact an angry or a sad plea of disagreement in response to the evaluation. We hypothesized that anger would have a 'smoothing' effect in interactions in which the evaluation content is competence (compared to when it is warmth), whereas sadness would have this effect when the evaluation content is warmth (compared to when it is competence).

\section{Method}

\section{Participants and design}

Ninety business students ( 45 women; $M_{\text {age }}=20.13$ years, $S D_{\text {age }}=1.30$ ) participated. They were randomly allocated to play the recruiter or the candidate role in one of four types of negative evaluation role-plays.

\section{Materials}

Role-play scenarios

To manipulate emotion congruency, we devised four role-plays. In all role-plays, the candidate always responded with disagreement to the negative evaluation and expressed the desire to prove to the recruiter the falseness of the test results. The 
role-plays varied according to two factors: the content of the recruiters' evaluation of the candidate (lack of warmth vs. lack of competence) and the emotional tone of the candidate (sad vs. angry). This resulted in two congruent and two incongruent roleplays.

The role-play started with the recruiter welcoming the candidate and the candidate introducing him/herself. Next, the recruiter rejects the candidate for the job and explains why:

What I will have to tell you is not easy. My final decision is not to hire you for this position. According to the test results, you do not have the right attitude for a company in which we value trust [competence] a lot. We are in a difficult sector and we need all our employees to be as humane and trustworthy [competent] as possible. I know that it is difficult for you to hear that, but we have several other candidates and we can only choose one. Do you understand what I mean?

As a response, the candidate responded with either a sad, or an angry plea of disagreement, saying:

You are making a decision based on tests that do not say anything about who I am. I am sad [angry]. You did not give me the opportunity to show who I am. I am a warm [competent] person. If you gave me another chance, I would prove it to you. Would you give me another chance?

Questions after the role-play

After the role-play, both candidates and recruiters indicated the extent to which candidates expressed anger ( 4 items, e.g., 'To what extent did the candidate [you] express anger?', Cronbach's $\alpha$ recruiters $=.89$; Cronbach's $\alpha$ candidates $=.91$ ) and sad ( 4 items, e.g., 'To what extent did the candidate [you] express sadness?', Cronbach's $\alpha$ recruiters $=.96$; Cronbach's $\alpha$ candidates $=.97$ ). These questions were asked to assess subjectively perceived emotion congruency.

\section{Dependent variables}

Next, perceived fluency of the role-play was assessed with three items, 'To what extent was the interview easy?', 'To what extent was the interview natural?' and 'To what extent was the interview in accordance with social norms?' (Cronbach's $\alpha$ recruiters $=.65$; Cronbach's $\alpha$ candidates $=.65$ ). All questions after the role-play were administered to both candidates and recruiters with a paper-and-pencil horizontal continuous scale of $8 \mathrm{~cm}$ wide, ranging from 'not at all' to 'very strongly'. Participants were simply asked to put a small vertical line crossing the horizontal line to indicate their opinion. We then measured the distance in $\mathrm{cm}$ between the left extreme of the scale and the line drawn by the participant.

\section{Procedure}

The study was conducted during a course about management. Students were told that they would participate in a role-play and were randomly assigned to play the role of the recruiter, or the role of the candidate. Each student received a written text that he/she memorized and then enacted. Dyads had to perform the role-play in one of the four 
corners of the classroom. Three to four dyads were acting at the same time in the same classroom. Recruiters were instructed to convey the message in a professional manner, while candidates were instructed to imagine themselves in a real situation and enact the emotion (i.e., sadness or anger) in a convincing manner. Recruiters and candidates did not know the text of the other actor in advance. After the role-play, participants filled in the questionnaire with dependent measures. The whole procedure lasted about $20 \mathrm{~min}$.

\section{Results}

\section{Preliminary analyses}

Because targets' responses were assessed in dyads, their responses are statistically nested within the dyads in which the experiment took place (Bryk \& Raudenbush, 1992). We checked for the existence of between-group variance with the SPSS Mixed procedure (version 17). This procedure tests the so-called null-model-an intercept-only model with no predictors specified - and allows the total variance to be partitioned into between- and within-group variance for the dependent variable. The results of this analysis showed that the between-group variance for our main dependent variable was .07, and non-significant $(p=.34)$. As the outcomes of a multilevel analysis would be in this case the same as the outcomes of a standard analysis of variance (Heck, Thomas, \& Tabata, 2010), we conducted all analyses using standard regression and variance analysis in SPSS 17.

\section{Effects of instructed congruency}

A 2 emotion congruency (congruent vs. incongruent) $\times 2$ role (candidate vs. recruiter) ANOVA, with fluency scores as the dependent variable, yielded a main effect of congruency, $F(1,86)=4.62, p=.034, \eta_{p}^{2}=.051$. As expected, emotion congruency $(M=1.88, S E=0.10)$ led to higher processing fluency of the interaction, than emotion incongruency $(M=1.57, S E=0.10)$. None of the other effects were significant, $F$ 's $<1$. Adding gender and its interactions with the other independent variables to the analysis did not change these results meaningfully; the main effect was still significant, $F(1$, 82) $=5.43, p=.022, \eta_{p}^{2}=.062 .^{2}$

Next, we further decomposed the effect of emotion congruency, with a two emotional reaction (sadness vs. anger) $\times 2$ evaluation content (warmth vs. anger) $\times 2$ role (candidate vs. recruiter) ANOVA, with fluency scores as the dependent variable. This analysis yielded a significant emotional reaction $\times$ evaluation content interaction effect, $F(1,82)=4.43, p=.038, \eta_{p}^{2}=.051$. It appeared that processing fluency was higher in competence-anger role-plays $(M=1.98, S E=0.14)$, than in warmth-anger role-plays $(M=1.50, S E=0.15)$. Moreover, processing fluency was higher in warmth-sadness roleplays $(M=1.78, S E=0.15)$ than in competence-sadness role-plays $(M=1.65$, $S E=0.15)$. Simple comparison tests revealed that the difference between the competence-anger and warmth-anger conditions was significant, $F(1,82)=5.33, p=.021$, $\eta_{p}^{2}=.063$. See Figure 3 .

\footnotetext{
${ }^{2} A$ third analysis in which we added dyad type (same-sex vs. cross-sex) and its interactions with the other independent variables did not change the direction of the effect either, $\mathrm{F}(I, 82)=3.63, \mathrm{p}=.060, \eta_{p}^{2}=.042$. The lower significance level could be due to low statistical power and/or to the possibility that cross-sex dyads $(\mathrm{M}=1.57, \mathrm{SE}=0.10)$ are perhaps less fluent, than samesex dyads $(\mathrm{M}=1.84, \mathrm{SE}=0.10), \mathrm{F}(I, 82)=3.11 \mathrm{I} \mathrm{p}=.081, \eta_{p}^{2}=.037$.
} 


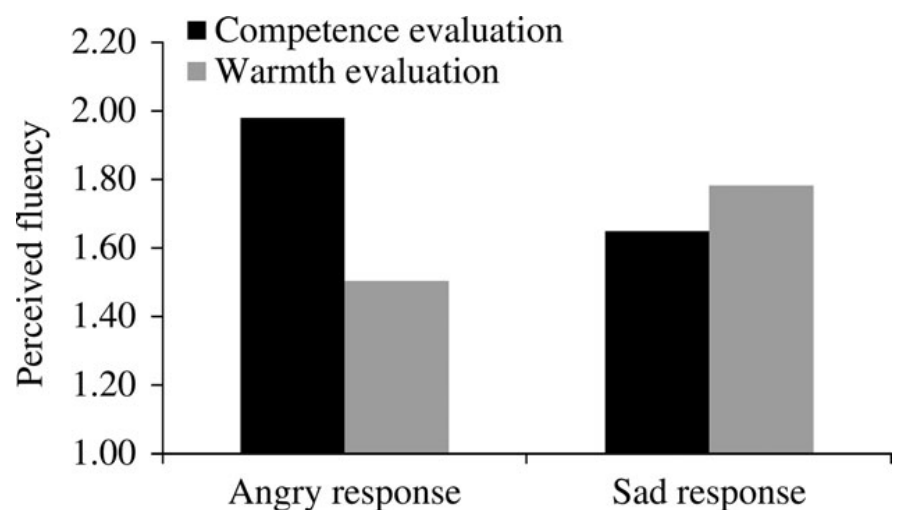

Figure 3. Anger led to higher perceptions of interaction fluency when it was in response to a negative competence evaluation, while sadness led to higher perceptions of interaction fluency when it was in response to a negative warmth evaluation.

\section{Effects of perceived congruency}

To further confirm above findings, we also conducted analyses to test the effects of subjectively perceived emotion congruency. Subjectively perceived emotion congruency was calculated by subtracting recruiters' and candidates' perceptions of anger from perceptions of sadness in the warmth condition, and by subtracting perceptions of sadness from perceptions of anger in the competence condition. Higher scores thus indicated higher perceived congruency.

In a linear regression analysis, processing fluency scores were regressed on the variable perceived congruency (continuous, mean centred), evaluation content (dummy coded: $0=$ warmth, $1=$ competence), and their interaction. This analysis revealed only a positive relation between perceived congruency and processing fluency $B=.247$, $S E=0.112, p=.030$. The interaction effect was not significant. This means that the more the candidates were perceived (and felt themselves) as acting emotionally congruent, the higher the processing fluency of the interaction was. The analysis with gender included did not change this effect $(B=.245, S E=0.114, p=.035)$, and no main effect of gender or interaction effects emerged ( $\phi$ 's $>.15)$.

\section{Discussion}

When sadness was expressed in response to a negative warmth evaluation, the interaction was perceived by both interaction partners as more natural, easier, and more conform social norms, than when it was expressed in response to a negative competence evaluation. For anger, the opposite was the case. These results suggest that recruiters and candidates intuitively felt that emotion congruency is more socially effective, than emotion incongruency.

\section{GENERAL DISCUSSION}

In the present paper, we investigated the potentially adaptive use of anger and sadness expressions by targets of a negative evaluation, in order to increase one's chances of being respected and valued again (De Cremer, 2002). Previous literature suggested that anger 
and sadness may be necessary to restore social bonds in the face of immediate relationship threat (Campos, Campos, \& Barrett, 1989; Campos, Mumme, Kermoian, \& Campos, 1994; Mikulincer, 1998). The question that we asked was, whether in addressing a negative evaluation, expressing anger, or sadness, would be the most effective.

Because previous research suggested that the functional properties of anger and sadness expressions are congruent with managing the competence and warmth aspects of social relationships (Çelik et al., 2013), we had hypothesized that a congruent emotional response that fits the specific concern voiced in the evaluation - that is, anger in response to a concern about the target's competence and sadness in response to a concern about the target's warmth - would be more effective than an incongruent emotional response. In line with literature on the social functionality of emotions (Ekman, 1992; Frijda, 2000; Tooby \& Cosmides, 2008; Van Kleef, 2010), our results showed that anger is more effective than sadness in response to a negative evaluation of competence, while sadness is more effective than anger in response to a negative evaluation of warmth.

Our findings are particularly compelling due to the different levels of analysis on which they were found. Not only were managers' perceptions of employees' competence and warmth positively affected by respectively anger and sadness expressions, they also estimated that they would doubt their (initial) negative perception of an employee more, when the employee would engage in congruent (vs. incongruent) emotional responding (Study 1). Furthermore, congruent emotional responding 'just felt right' for both evaluators and targets when targets were instructed to enact congruent emotions in a staged negative evaluation interview (Study 2).

Our results extend previous findings that stressed the importance of congruency between the valence of message content and non-verbal expression. In a study conducted by Newcombe and Ashkanasy (2002), participants viewed videotapes of leaders giving positive and negative feedbacks, with facial expressions of affect that were either congruent or incongruent with the valence of the verbal message that they were delivering. Results indicated that message congruent leaders were rated most positively. In our current studies, we moved beyond intra-individual valence congruency between emotion expression and verbal content, to an interindividual congruency between discrete emotion expressions and interpersonal evaluations.

Our study follows a relatively new trend in emotion literature that views the functionality of emotions not only at the intrapersonal level of analysis - the key question being how individuals are affected by the emotions they experience - but also at the interpersonal level. With our research, we contribute to the literature on how emotions can influence other people's cognitions and perceptions (Côte \& Hideg, 2011; Van Kleef et al., 2011).

\section{Implications}

The current results have several theoretical and practical implications. First, from a theoretical perspective, our results imply that anger and sadness are not solely associated with respectively hostility or power display, and weakness or passivity (Izard \& Ackerman, 2004; Rucker \& Petty, 2004; Tiedens, 2001). If anger were only associated with hostility, we would have found that sadness, overall, has more positive effects than anger, but this was not the case. Likewise, if sadness were only associated with weakness or passivity, we would have found that anger overall has more positive effects than sadness, but this was also not the case. Sadness appeared to be equally persuasive as anger, provided that it was expressed in response to a negative warmth evaluation. This is 
interesting, because in the literature it is often anger that is associated with persuasiveness, not sadness (Frank, 1988). Our results suggest that anger and sadness expressions that are congruent with the content of interpersonal evaluations can be considered a form of social competence (Schneider, Ackerman, \& Kanfer, 1996). In other words, anger and sadness can be functional tools that support one's verbal messages of relationship intentions, and are ultimately tools for social influence (Van Kleef et al., 2011).

This is of course not to say that other factors are not in play, and should not be taken in to account when determining the social effectiveness of sadness and anger expressions in social interactions. For example, differences in relative status between interaction partners (Aquino, Tripp, \& Bies, 2001), gendered expectations (Timmers et al., 1998), or the specific social context in which a negative evaluation takes place, can all jointly affect to what extent anger and sadness will have desired social outcomes. Nevertheless, with our studies we demonstrated the importance of a factor that has not been considered before: the congruency between the expressed emotion and the evaluation content.

From a practical point of view, one may wonder whether social display rules that discourage and prevent individuals from expressing negative emotions (Kramer \& Hess, 2002) should not be more flexible. Anger indeed has an overly negative image in research (Tavris, 1989), as well as in society (Averill, 1983), and one wonders whether the negative implications of anger expression and inappropriate expressions of it perhaps stem from the very inacceptance surrounding it. It may be possible that in adopting an open attitude towards receiving negative emotions in response to giving a negative evaluation, the outcome of a negative evaluation conversation could be surprisingly reassuring (see also, Taylor \& Bright, 2011). We say 'surprisingly' and 'reassuring', because the results of Study 1 perfectly demonstrate the duality, and social delicacy, surrounding anger expressions; on the one hand, anger emerged as a socially undesirable emotion - as was evidenced by managers assigning higher warmth and competence to employees expressing sadness but on the other hand, when the evaluation concerned employees' competence, angry employees were considered as more persuasive than sad employees. Thus, it seems that even though at some level managers may denounce anger, anger can sometimes be more persuasive than sadness in making one reconsider an initially negative opinion about the anger expresser.

\section{Limitations}

One limitation of our studies is that we did not include experimental conditions in which targets responded with positive emotions or, with a neutral emotional tone. Therefore, we cannot make any claims about whether expressing negative emotions is particularly more persuasive than, for example, remaining emotionally neutral or positive. In our studies, we stripped down the response to the evaluation to focusing only on the negative emotions. We recognize that in reality, human conversations are much richer, both verbally and non-verbally (i.e., emotionally). However, we would suspect that an exclusively positive and reassuring attitude on the side of the target of the evaluation could appear as somewhat arrogant, and give the impression of disregard for the evaluator's opinion, if it is not also accompanied by some sign of being worried by the negative evaluation. Note that we do not assert that a positive and reassuring attitude needs to be avoided all together. On the contrary, being positive at some moment in the conversation is probably essential as well, but it is perhaps not enough to achieve the desired goal - that is, to be seen as competent and/or warm. We would also argue that showing no trace of emotion in response to a bad evaluation is often impossible in real-life situations; emotions 
often seep through in one's non-verbal behaviour (Ekman \& Friesen, 1969). Needless to say, if our emotions are going to seep through, we might as well benefit from them by expressing them in a controlled and strategic manner. In our view, an effective response is a response that communicates that the message is taken at heart, which necessitates a response of social pain (Eisenberger \& Lieberman, 2004), but nonetheless carefully regulated and chosen to address the content of the evaluation.

Another potential limitation is that we relied on hypothetical scenarios and role-play. We acknowledge that these methods suffer from ecological validity and replications in more realistic settings are certainly very important. Nevertheless, a strength of, for example, Study 1 is that our participants were real-life managers. Moreover, using hypothetical scenarios it was possible to strip down the context of interest to the core concepts that we were interested in, ridding it from potentially confounding factors. The strength of Study 2 is that it assessed perceptions of fluency, which can be considered a relatively intuitive perception, and in combination with our between-subjects design, this should have minimize socially desirable responding. Nevertheless, we encourage future research to replicate our findings in more realistic and socially richer settings that allow taking into account other potentially moderating variables, some of which we mentioned above.

Finally, in our approach we used two different dependent variables that are conceptually related, to assess the social effectiveness of anger and sadness expressions. More direct replications with both dependent variables are thus necessary to be able to make a stronger claim. However, a strength of this approach is that it extends findings to a wider range of social outcomes, and we show that the effect of emotion congruency does not only take place on a relatively rational level (i.e., perceived persuasiveness), but also on the more intuitive level of perceived interaction fluency.

\section{Future directions}

Tamir and Ford (2012) showed that people sometimes prefer to be angry if they believe it will bring them benefits. In another study, they showed that people who are willing to feel anger strategically are more emotionally intelligent (Ford \& Tamir, 2012). Follow-up studies could investigate whether congruent sadness and anger expressions are also related to emotional intelligence, and perhaps could even have long-term consequences on other indicators of well-being, like, for example, feelings of social and/or personal self-efficacy (Gundlach, Martinko, \& Douglas, 2003; Heuven, Bakker, Schaufeli, \& Huisman, 2006).

Another interesting venue for future research could be to investigate whether interventions that increase awareness of the social functions of anger and sadness could increase tolerance for expressing these emotions in delicate (i.e., formal) social interactions. Indeed, previous research has indicated a general reluctance surrounding negative evaluation conversations, with individuals often fearing a defensive response, and/or retaliation from targets of the evaluation (Bond \& Anderson, 1987; Folger \& Skarlicki, 1998; Tesser \& Rosen, 1975). These fears ironically enough may fuel hostile responses when one is confronted with an emotional response. Moreover, research shows that excessive inhibition of negative emotions at, for example, work can lead to burnout (Zapf \& Holz, 2006). Seeing that evaluations are part of almost every domain in life, it is important to investigate how negative emotion expression could gain in social acceptance, and importantly, also how people can be thought to express their negative emotions more constructively and strategically. 


\section{References}

Alter, A. L., \& Oppenheimer, D. M. (2009). Uniting the tribes of fluency to form a meta-cognitive nation. Personality and Social Psychology Review, 13, 219-235. doi:10.1177/108886 8309341564

Aquino, K., Tripp, T. M., \& Bies, R. J. (2001). How employees respond to personal offense: The effects of blame attribution, victim status, and offender status on revenge and reconciliation in the workplace. Journal of Applied Psychology, 86, 52-59. doi:10.1037/0021-9010.86.1.52

Averill, J. R. (1983). Studies on anger and aggression: Implications for theories of emotion. American Psychologist, 38, 1145-1160. doi:10.1037/0003-066X.38.11.114

Baumeister, R. F. (1982). Self-esteem, self-presentation, and future interaction: A dilemma of reputation. Journal of Personality, 50, 29-45. doi:10.1111/j.1467-6494.1982.tb00743.x

Bond, C. F. Jr, \& Anderson, E. L. (1987). The reluctance to transmit bad news: Private discomfort or public display? Journal of Experimental Social Psychology, 23, 176-187. doi:10.1016/00221031(87)90030-8

Brown, C. M., \& McConnell, A. R. (2011). Discrepancy-based and anticipated emotions in behavioral self-regulation. Emotion, 11, 1091-1095. doi:10.1037/a0021756

Bryk, A. S., \& Raudenbush, S. W. (1992). Hierarchical linear models. Newbury Park, CA: Sage.

Burgoon, J. K., Guerrero, L. K., \& Manusov, V. (2011). Nonverbal signals. In M. L. Knapp \& J. A. Daly (Eds.), The Sage handbook of interpersonal communication (4th ed.). (pp. 239-282). Thousand Oaks, CA: Sage.

Butler, E. A., Egloff, B., Wilhelm, F. H., Smith, N. C., Erickson, E. A., \& Gross, J. J. (2003). The social consequences of expressive suppression. Emotion, 3, 48-67. doi:10.1037/15283542.3.1.48

Campos, J. J., Campos, R. G., \& Barrett, K. C. (1989). Emergent themes in the study of emotional development and emotion regulation. Developmental Psychology, 25, 394-402. doi:10.1037/ 0012-1649.25.3.394

Campos, J. J., Mumme, D. L., Kermoian, R., \& Campos, R. G. (1994). A functionalist perspective on the nature of emotion. Monographs of the Society for Research in Child Development, 59, 284303. doi:10.1111/j.1540-5834.1994.tb01289.x

Çelik, P., Lammers, J., Van Beest, I., Bekker, M. H. J., \& Vonk, R. (2013). Not all rejections are alike: Competence and warmth as a fundamental distinction in social rejection. Journal of Experimental Social Psychology, 49, 635-642. doi:10.1016/j.jesp.2013.02.010

Conte, H. R., \& Plutchik, R. (1981). A Circumplex model for interpersonal personality traits. Journal of Personality and Social Psychology, 40, 701-720. doi:10.1037/0022-3514.40.4.701

Cosmides, L., \& Tooby, J. (2000). Evolutionary psychology and the emotions. In M. Lewis \& J. M. Haviland-Jones (Eds.), Handbook of emotions (pp. 91-115). New York, NY: Guilford Press.

Côte, S., \& Hideg, I. (2011). The ability to influence others via emotion displays: A new dimension of emotional intelligence. Organizational Psychology Review, 1, 53-71. doi:10.1177/ 2041386610379257

Cuddy, A. J. C., Fiske, S. T., \& Glick, P. (2008). Warmth and competence as universal dimensions of social perception: The stereotype content model and the BIAS map. Advances in Experimental Social Psychology, 40, 61-149. doi:10.1016/S0065-2601(07)00002-0

De Cremer, D. (2002). Respect and cooperation in social dilemmas: The importance of feeling included. Personality and Social Psychology Bulletin, 28, 1335-1341. doi:10.1177/ 014616702236830

Eisenberger, N. I., \& Lieberman, M. D. (2004). Why rejection hurts: A common neural alarm system for physical and social pain. Trends in Cognitive Sciences, 8, 294-300. doi:10.1016/ j.tics.2004.05.010

Ekman, P. (1992). An argument for basic emotions. Cognition E Emotion, 6, 169-200. doi:10.1080/ $\underline{02699939208411068}$

Ekman, P. (2003). Emotions revealed. New York, NY: Times Books.

Ekman, P., \& Friesen, W. V. (1969). Non-verbal leakage and clues to deception. Psychiatry, 32, 88-106. doi:10.1521/00332747.1969.11023575 
Fiske, S. T., Cuddy, A. J. C., \& Glick, P. (2007). Universal dimensions of social cognition: Warmth and competence. Trends in Cognitive Sciences, 11, 77-83. doi:10.1016/j.tics.2006.11.005

Folger, R., \& Skarlicki, D. P. (1998). When tough times make tough bosses: Managerial distancing as a function of lay-off blame. Academy of Management Journal, 41, 79-87. doi:10.2307/256899

Ford, B. Q., \& Tamir, M. (2012). When getting angry is smart: Emotional preferences and emotional intelligence. Emotion, 12, 685-689. doi:10.1037/a0027149

Frank, R. H. (1988). Passions within reason: The strategic role of the emotions. New York, NY: Norton.

Frijda, N. H. (2000). The psychologists' point of view. In M. Lewis \& J. M. Haviland (Eds.), Handbook of emotions (2nd ed.) (pp. 59-74). New York, NY: Guilford Press.

Gray, H. M., Ishii, K., \& Ambady, N. (2011). Misery loves company: When sadness increases the desire for social connectedness. Personality and Social Psychology Bulletin, 37, 1438-1448. doi:10.1177/0146167211420167

Gross, J. J., \& John, O. P. (2003). Individual differences in two emotion regulation processes: Implications for affect, relationships, and well-being. Journal of Personality and Social Psychology, 85, 348-362. doi:10.1037/0022-3514.85.2.348

Gundlach, M. J., Martinko, M. J., \& Douglas, S. C. (2003). Emotional intelligence, causal reasoning, and the self-efficacy development process. The International Journal of Organizational Analysis, 11, 229-246. doi:10.1108/eb028974

Heck, R. H., Thomas, S. L., \& Tabata, L. (2010). Multilevel and longitudinal analysis using SPSS. New York, NY: Routledge/Taylor \& Francis.

Heuven, E., Bakker, A. B., Schaufeli, W. B., \& Huisman, N. (2006). The role of self-efficacy in performing emotion work. Journal of Vocational Behavior, 69, 222-235. doi:10.1016/ j.jvb.2006.03.002

Horowitz, L. M., \& Sales French, R. (1979). Interpersonal problems of people who describe themselves as lonely. Journal of Consulting and Clinical Psychology, 47, 762-764. doi:10.1037/0022-006X.47.4.762

Ilgen, D., \& Davis, C. (2000). Bearing bad news: Reactions to negative performance feedback. Applied Psychology, 49, 550-565. doi:10.1111/1464-0597.00031

Izard, C., \& Ackerman, B. P. (2004). Motivational, organizational, and regulatory functions of discrete emotions. In M. Lewis \& J. M. Haviland-Jones (Eds.), Handbook of emotions (pp. 253-264). New York, NY: Guilford Press.

Jussim, L., Yen, H., \& Aiello, J. R. (1995). Self-consistency, self-enhancement, and accuracy in reactions to feedback. Journal of Experimental Social Psychology, 31, 322-356. doi:10.1006/ jesp.1995.1015

Kassinove, H., Roth, D., Owens, S. G., \& Fuller, J. R. (2002). Effects of trait anger and anger expression style on competitive attack responses in a wartime prisoner's dilemma game. Aggressive Behavior, 28, 117-125. doi:10.1002/ab.90013

Keltner, D., \& Haidt, J. (1999). Social functions of emotions at four levels of analysis. Cognition and Emotion, 13, 505-521. doi:10.1080/026999399379168

Knutson, B. (1996). Facial expressions of emotion influence interpersonal trait inferences. Journal of Nonverbal Behavior, 20, 165-182. doi:10.1007/BF02281954

Kramer, M. W., \& Hess, J. A. (2002). Communication rules for the display of emotions in organizational settings. Management Communication Quarterly, 16, 66-80. doi:10.1177/ 0893318902161003

Leary, M. R., Springer, C., Negel, L., Ansell, E., \& Evans, K. (1998). The causes, phenomenology, and consequences of hurt feelings. Journal of Personality and Social Psychology, 74, 1225-1237. doi:10.1037/0022-3514.74.5.1225

Lelieveld, G. J., Van Dijk, E., Van Beest, I., \& Van Kleef, G. A. (2012). Why anger and disappointment affect others bargaining behavior differently: The moderating role of power and the mediating role of reciprocal and complementary emotions. Personality and Social Psychology Bulletin, 38, 1209-1221. doi:10.1177/0146167212446938 
Metts, S., \& Grohskopf, E. (2003). Impression management: Goals, strategies, and skills. In J. O. Greene \& B. R. Burleson (Eds.), Handbook of communication and social interaction skills (pp. 357-399). Mahwah, NY: Laurence Erlbaum.

Mikulincer, M. (1998). Adult attachment style and affect regulation: Strategic variations in selfappraisals. Journal of Personality and Social Psychology, 75, 420-435. doi:10.1037/00223514.75.2.420

Newcombe, M. J., \& Ashkanasy, N. M. (2002). The role of affect and affective congruence in perceptions of leaders: An experimental study. The Leadership Quarterly, 13, 601-614. doi:10.1016/S1048-9843(02)00146-7

Orford, J. (1986). The rules of interpersonal complementarity: Does hostility beget hostility and dominance, submission? Psychological Review, 93, 365-377. doi:10.1037/0033-295X.93.3.365

Pearson, A. R., \& Dovidio, J. F. (2013). Intergroup fluency: How processing experiences shape intergroup cognition and communication. In J. P. Forgas, J. Laszlo \& O. Vincze (Eds.), Social cognition and communication. New York, NY: Psychology Press.

Reber, R., Meier, B., Ruch-Monachon, M. A., \& Tiberini, M. (2006). Effects of processing fluency on comparative performance judgments. Acta Psychologica, 123, 337-354. doi:10.1016/j.actpsy. 2006.02.001

Rucker, D. D., \& Petty, R. E. (2004). Emotion specificity and consumer behavior: Anger, sadness, and preference for activity. Motivation and Emotion, 28,3-21. doi:10.1023/B:MOEM.0000027275. 95071.82

Schneider, R. J., Ackerman, P. L., \& Kanfer, R. (1996). To "act wisely in human relations": Exploring the dimensions of social competence. Personality and Individual Differences, 21, 469-481. doi:10.1016/0191-8869(96)00084-0

Shaver, P., Schwartz, J., Kirson, D., \& O'Connor, C. (1987). Emotion knowledge: Further exploration of a prototype approach. Journal of Personality and Social Psychology, 52, 1061-1086. doi:10.1037/0022-3514.52.6.1061

Sinaceur, M., \& Tiedens, L. Z. (2006). Get mad and get more than even: When and why anger expression is effective in negotiations. Journal of Experimental Social Psychology, 42, 314322. doi:10.1016/j.jesp.2005.05.002

Tamir, M., \& Ford, B. Q. (2012). When feeling bad is expected to be good: Emotion regulation and outcome expectancies in social conflicts. Emotion, 12, 807-816. doi:10.1037/a0024443

Tavris, C. (1989). Anger: The misunderstood emotion. New York, NY: Simon \& Schuster.

Taylor, S. N., \& Bright, D. S. (2011). Open-mindedness and defensiveness in multisource feedback processes: A conceptual framework. The Journal of Applied Behavioral Science, 47, 432-460. doi:10.1111/10.1177/0021886311408724

Tesser, A., \& Rosen, S. (1975). The reluctance to transmit bad news. Advances in Experimental Social Psychology, 8, 193-232. doi:10.1016/0022-1031(87)90030-8

Tiedens, L. Z. (2001). Anger and advancement versus sadness and subjugation: The effect of negative emotion expressions on social status conferral. Journal of Personality and Social Psychology, 80, 86-94. doi:10.1037/0022-3514.80.1.86

Tiedens, L. Z., Ellsworth, P. C., \& Mesquita, B. (2000). Stereotypes about sentiments and status: Emotional expectations for high- and low-status group members. Personality and Social Psychology Bulletin, 26, 560-574. doi:10.1177/0146167200267004

Timmers, M., Fischer, A. H., \& Manstead, A. S. (1998). Gender differences in motives for regulating emotions. Personality and Social Psychology Bulletin, 24, 974-985. doi:10.1177/ 0146167298249005

Tooby, J., \& Cosmides, L. (2008). The evolutionary psychology of the emotions and their relationship to internal regulatory variables. In M. Lewis, J. M. Haviland-Jones \& L. F. Barrett (Eds.), Handbook of emotions (3rd ed.). (pp. 114-137). New York, NY: Guilford Press.

Van Beest, I., Van Kleef, G. A., \& Van Dijk, E. (2008). Get angry, get out: The interpersonal effects of anger communication in multi-party negotiation. Journal of Experimental Social Psychology, 44, 993-1002. doi:10.1016/j.jesp.2008.02.008 
Van Kleef, G. A. (2010). Don't worry, be angry? Effects of anger on feelings, thoughts, and actions in conflict and negotiation. In M. Potegal, G. Stemmler \& C. Spielberg (Eds.), Handbook of anger (pp. 545-560). New York, NY: Springer.

Van Kleef, G. A., Van Doorn, E. A., Heerdink, M. W., \& Koning, L. F. (2011). Emotion is for influence. European Review of Social Psychology, 22, 114-163. doi:10.1080/10463283.2011.627192

Vingerhoets, A. J. J. M., Cornelius, R. R., Van Heck, G. L., \& Becht, M. C. (2000). Adult crying: A model and review of the literature. Review of General Psychology, 4, 354-377. doi:10.1037/10892680.4.4.354

Wiggins, J. S. (1979). A psychological taxonomy of trait-descriptive terms: The interpersonal domain. Journal of Personality and Social Psychology, 37, 395-412. doi:10.1037/00223514.37.3.395

Wish, M., Deutsch, M., \& Kaplan, S. J. (1976). Perceived dimensions of interpersonal relations. Journal of Personality and Social Psychology, 33, 409-420. doi:10.1037/0022-3514.33.4.409

Zapf, D., \& Holz, M. (2006). On the positive and negative effects of emotion work in organizations. European Journal of Work and Organizational Psychology, 15, 1-28. doi:10.1080/ 13594320500412199

Zeifman, D. M. (2001). An ethological analysis of human infant crying: Answering Tinbergen's four questions. Developmental Psychobiology, 39, 265-285. doi:10.1002/dev.1005

Zitek, E. M., \& Tiedens, L. Z. (2012). The fluency of social hierarchy: The ease with which hierarchical relationships are seen, remembered, learned, and liked.Journal of Personality and Social Psychology, 102, 98-115. doi:10.1037/a0025345

Received I4 November 2015; revised version received 30 May 2016 